\title{
Decreases in cerebral saturation in patients with septic shock are associated with increased risk of death: a prospective observational single center study
}

\author{
Duane J. Funk ${ }^{1,2^{*}}$, Anand Kumar ${ }^{1}$ and Gregory $\mathrm{Klar}^{1}$
}

\begin{abstract}
Background: The mortality rate from septic shock has been declining. Cerebral hypoxia, measured non-invasively with cerebral oximetry, has been correlated with neurologic and non-neurologic sequelae. Whether cerebral desaturations occur in septic shock patients and what consequences these may have is untested.

Methods: Adult patients with septic shock had cerebral saturation monitoring initiated. The primary objective was to determine if the incidence and magnitude of cerebral desaturations in septic shock patients correlated with delirium. We also compared the incidence and magnitude of cerebral desaturations in patients with septic shock with patients undergoing high-risk non-cardiac surgical procedures, a group known to be at high risk for cerebral desaturations.

Results: Fifteen patients were enrolled. Twelve (80 \%) patients had a decrease in $\mathrm{SctO}_{2}$ below $65 \%$. Delirium was not associated with the area under the curve of an $\mathrm{SctO}_{2}$ of $65 \%(p=0.84)$.

Patients who died of septic shock had more significant decreases in $\mathrm{SctO}_{2}$ than those who survived $(p=0.04)$.

Decreased $\mathrm{SctO}_{2}$ was more common in patients with septic shock and was of greater magnitude than those undergoing high-risk non-cardiac surgery.

Conclusions: Cerebral desaturations occur more commonly and are of a greater magnitude in septic shock patients compared with those undergoing high-risk non-cardiac surgery. There did not appear to be a relationship between the incidence or magnitude of decreases in $\mathrm{SctO}_{2}$ and ICU delirium. Patients who died of septic shock had more significant decreases in $\mathrm{SctO}_{2}$ than patients who survived.
\end{abstract}

Keywords: Septic shock, Cerebral oxygen saturation, Monitoring

\section{Background}

Over the past 15 years, the mortality rate from severe sepsis and septic shock has been declining [1-5]. With this decreased mortality rate, clinicians are now focusing increasing efforts on reducing sepsis-related morbidity, including intensive care unit (ICU)-acquired delirium.

Delirium in the ICU is a prevalent problem, occurring in up to $80 \%$ of patients [6]. The etiology is thought to be multifactorial including the effects of lack of sleep, noise in the ICU, use of sedatives and analgesics, and

\footnotetext{
* Correspondence: funk@cc.umanitoba.ca

'University of Manitoba, Winnipeg, Canada

${ }^{2}$ Department of Medicine, Section of Critical Care, College of Medicine,

Faculty of Health Sciences, University of Manitoba, Winnipeg, Canada
}

sepsis related to infection [7-9]. Cerebral hypoxia could be a potential cause of delirium in ICU patients. There is emerging data from the anesthesia literature suggesting that occult intraoperative cerebral hypoxia results in postoperative morbidity, including postoperative cognitive dysfunction [10-13]. These decreases in brain tissue oxygen saturation $\left(\mathrm{SctO}_{2}\right)$ can be measured noninvasively with cerebral oximetry. In the operative environment, cerebral desaturations usually occur in the absence of systemic hypoxemia [13]. The question of whether cerebral desaturations occur in ICU patients (and in particular, septic shock patients) and what, if any, consequences these may have is untested. 
During the resuscitative phase of septic shock, a low cardiac output state occurs. During these low flow states, the regional distribution of blood flow to vital organs such as the brain occurs at the expense of other tissue beds such as the kidney and splanchnic circulation $[14,15]$. A reliable non-invasive continuous perfusion monitor has not been utilized in patients with shock.

In this single-center prospective observational trial, our primary objective was to determine if the incidence and magnitude of cerebral desaturations in septic shock patients correlated with delirium, as measured by the Confusion Assessment Method for the Intensive Care Unit (CAM-ICU) score [16]. Secondary outcomes examined were the association between the incidence and magnitude of cerebral desaturations and acute kidney injury (AKI) or death (up to 28 days after the diagnosis of sepsis). We also compared the incidence and magnitude of cerebral desaturations in patients with septic shock with patients undergoing high-risk non-cardiac surgical procedures, a group known to be at high risk for cerebral desaturations and high risk for complications $[10,17]$.

\section{Methods}

This trial was registered at Clinicaltrials.gov as NCT1836302. After approval by the University of Manitoba Biomedical Research Ethics Board, we recruited all patients over the age of 18 years who had been admitted to either the Medical or Surgical/Trauma ICU at the University of Manitoba Health Sciences Center with the diagnosis of severe sepsis and septic shock for a 6-month period. Written consent for inclusion in the study was obtained from the patient's family on a deferred basis.

The definition of severe sepsis and septic shock was based on the American College of Chest Physicians/Society of Critical Care Medicine Consensus Conference Committee [18]. Patients were treated according to the Surviving Sepsis Guidelines with early antimicrobial therapy and source control, aggressive fluid resuscitation, mechanical ventilation, and hemodynamic support [19].

Patients with severe sepsis and septic shock had bilateral near-infrared spectroscopic cerebral oximiter sensors (Foresight ${ }^{\circ}$, CASMED, Brandford, CT, USA) placed on their forehead. Sensors were placed within $12 \mathrm{~h}$ of the patients being admitted to the ICU in order to capture any desaturations that might occur during the resuscitative phase of their septic shock. Sensors were kept in place for at least $24 \mathrm{~h}$, with a maximum monitoring time of $48 \mathrm{~h}$. If a patient regained hemodynamic stability (as defined as no longer needing vasopressor support) after $24 \mathrm{~h}$, monitoring was discontinued. The monitoring was also discontinued and reinstituted in order to facilitate travel for diagnostic imaging or other procedures outside the ICU.

Cerebral saturation data were collected continuously at $0.5 \mathrm{~Hz}$. After the study period ended, the data were downloaded from the monitor and placed into a Microsoft Excel (Redmond, WA) spreadsheet and the values were averaged on an hourly basis. Hemodynamic values and vasopressor doses were recorded hourly.

Patients were sedated to a RASS goal of -1 to -2 as per institutional protocol (typically with a combination of either propofol, fentanyl, or midazolam infusions). The CAM-ICU assessment was measured twice daily for the duration of ICU stay. Daily interruption of sedation was not performed. The CAM-ICU assessment occurred for several more days after $\mathrm{SctO}_{2}$ monitoring was discontinued in an attempt to capture the potential for delayed effects of decreases in $\mathrm{SctO}_{2}$ on the incidence of delirium.

Baseline demographic data on each patient was collected. In addition to $\mathrm{SctO}_{2}$, levels, other patient variables that were collected included hourly blood pressure, hourly vasopressor requirements, fraction of inspired oxygen, and peripheral oxygen saturation. Sequential organ failure assessment (SOFA) and the Acute Physiology and Chronic Health Evaluation II (APACHE II) scores were also collected for each patient.

Outcome variables measured included the presence of delirium as determined by a positive Confusion Assessment Method for the Intensive Care Unit (CAM-ICU) score, acute kidney injury (using the AKIN criteria [20]), the need for two or more vasopressors/inotropes, and ICU mortality.

As a comparator group, the incidence and magnitude of cerebral desaturations was compared with data from a concurrent trial of patients undergoing high-risk noncardiac surgical procedures utilizing the same monitor (NCT01838733). This is a patient group that is known to be at high risk for cerebral desaturations [10, 17].

\section{Availability of data and materials}

Our research ethics board does not allow the release of databases without consent. These will not be available to readers.

\section{Statistical analysis}

As the definition of cerebral desaturation varies from study to study, we examined several exploratory markers of desaturation including overall number of desaturations (to less than $<65 \%$ ), nadir cerebral saturation $\left(\mathrm{SctO}_{2}\right)$, percent time under threshold (defined as the percentage of time spent below an $\mathrm{SctO}_{2}$ level of $65 \%$, to account for variable recording lengths between patients), and the area under threshold (AUT; a measurement that takes into account the time below a 
threshold, as well as the magnitude of the decrease in $\mathrm{SctO}_{2}$, units of \%-min). Values of AUT were divided by the total recording time for patients to obtain values on a per hour basis to take into account the varied recording times.

In examining the relationship between changes in hemoglobin level and $\mathrm{SctO}_{2}$, we examined various $\mathrm{SctO}_{2}$ thresholds at $5 \%$ intervals $(60-75 \%)$ to determine which cutoff had the highest correlation with change in day 2 hemoglobin.

As this was a pilot study, we calculated our sample size based on the method of Viechtbauer et al. [21]. A previous work in high-risk surgical patients has demonstrated a cerebral desaturation rate of $20 \%$ [10, 12, 17, $22,23]$. Assuming a similar incidence in patients with septic shock, we determined that studying 14 patients would give us $95 \%$ confidence to detect a $20 \%$ probability of desaturations.

Statistical analysis was performed using GraphPad Prism version 6.0 (GraphPad Software Inc., La Jolla, CA, USA). Categorical variables were analyzed with the Fisher exact test. Between group continuous variables were analyzed with a Student $t$ test or a Mann-Whitney $U$ test, depending on the distribution of the data. The Kolmogorov-Smirnov test was performed to assess for normality. Continuous data are presented as mean \pm standard deviation or median [interquartile range]. Correlations between $\mathrm{SctO}_{2}$ and SOFA and APACHE II scores were compared using a Spearman correlation test. A $p$ value of 0.05 was considered significant.

\section{Results}

During our 6-month pilot trial, we enrolled 15 patients with septic shock (see Tables 1 and 2). The average age of the patients was $57 \pm 14$ years. Median [interquartile range] for SOFA and APACHE II scores were 15 [12-19] and 23 [18-26], respectively. Pneumonia was the most common cause of sepsis, occurring in seven out of the 15 (47\%) patients. Eight of the 15 patients (53\%) had a causative organism identified (see Table 1). Thirteen of the patients $(87 \%)$ were mechanically ventilated and all were receiving vasopressor support with norepinephrine. Ten $(67 \%)$ were also receiving concomitant therapy with vasopressin. Seven of the 15 patients ( $47 \%$ ) were CAM-ICU positive, and 10 developed an AKI. There were four deaths in the septic shock group.

Patients in the septic shock group were monitored for an average of $39.8 \pm 20.4 \mathrm{~h}$. Twelve (80 \%) of the septic shock patients had a decrease in their $\mathrm{SctO}_{2}$ to below $65 \%$. Six had decreases in their $\mathrm{SctO}_{2}$ to below $60 \%$.

There was no difference between the CAM-ICU positive and CAM-ICU negative groups with respect to the percentage of time spent below an $\mathrm{SctO}_{2}$ of $65 \%$ nor the area under a threshold $\mathrm{SctO}_{2}$ of $65 \%$ (see Table 3, all $p$ values $>0.05$ ).

There was also no difference in the percentage of time spent below an $\mathrm{S}_{\mathrm{ct}} \mathrm{O}_{2}$ of $65 \%$ in patients who did and did not suffer an AKI. The AUT of an $\mathrm{S}_{\mathrm{ct}} \mathrm{O}_{2}<65 \%$ was also not different between the patients with and without an AKI (Table 3).

Table 1 Baseline data for the patients with septic shock

\begin{tabular}{|c|c|c|c|c|c|c|c|c|c|}
\hline Patient & $\mathrm{PMHX}$ & Source of sepsis & Organism & Outcome & CAM & AKI & SOFA & APACHE & $\begin{array}{l}\text { Mechanical } \\
\text { ventilation }\end{array}$ \\
\hline 1 & EtOH abuse & Lung & None recovered & Dead & $\mathrm{CAM}+$ & Yes & 23 & 24 & Yes \\
\hline 2 & HIV, IHD & Lung & Streptococcus pneumoniae & Alive & CAM- & Yes & 15 & 28 & Yes \\
\hline 3 & $\mathrm{CHF}$ & Lung & None recovered & Alive & $\mathrm{CAM}+$ & Yes & 17 & 24 & Yes \\
\hline 4 & None & Heart/lung & Staphylococcus aureus & Alive & CAM+ & Yes & 18 & 19 & Yes \\
\hline 5 & IVDU, Hep C & Bacteremia & GNB & Dead & CAM+ & Yes & 22 & 26 & Yes \\
\hline 6 & None & Abdomen & None recovered & Alive & CAM+ & No & 10 & 15 & Yes \\
\hline 7 & Pancreatitis, EtOH, DM2 & Abdomen & None recovered & Alive & CAM- & No & 8 & 16 & Yes \\
\hline 8 & Smoker, Asthma & Lung & None recovered & Alive & CAM- & No & 15 & 18 & Yes \\
\hline 9 & DM2, HTN, IHD, UGIB & Lung & Pseudomonas sp. & Alive & CAM- & Yes & 15 & 30 & Yes \\
\hline 10 & None & Lung & None recovered & Alive & CAM- & No & 6 & 9 & No \\
\hline 11 & $\mathrm{DM} 2, \mathrm{CMP}, \mathrm{COPD}$ & Ischemic foot & S. aureus & Dead & CAM+ & Yes & 20 & 26 & Yes \\
\hline 12 & $\mathrm{CHF}, \mathrm{CRI}, \mathrm{RA}$ & Necrotizing fasciitis & Pseudomonas & Dead & CAM- & Yes & 19 & 23 & Yes \\
\hline 13 & $\mathrm{DM} 2, \mathrm{PVD}$ & Leg & $\beta$-hemolytic strep & Alive & CAM- & Yes & 13 & 21 & Yes \\
\hline 14 & Developmental delay & Abdomen & Non-hemolytic Streptococcus & Alive & CAM- & Yes & 12 & 27 & Yes \\
\hline 15 & $\begin{array}{l}\text { Autoimmune hepatitis, } \\
\text { portal HTN, ESRD }\end{array}$ & Ankle & None recovered & Alive & CAM+ & No & 16 & 23 & No \\
\hline
\end{tabular}

PMHx past medical history, CAM-ICU confusion assessment method, AKI acute kidney injury, EtOh ethanol, HIV human immunodeficiency virus, IHD ischemic heart disease, $C H F$ congestive heart failure, IVDU intravenous drug use, HEP C hepatitis $C$ virus, DM2 type 2 diabetes, HTN hypertension, UGIB upper gastrointestinal bleed, CMP cardiomyopathy, COPD chronic obstructive pulmonary disease, CRI chronic renal insufficiency, RA rheumatoid arthritis, PVD peripheral vascular disease, ESRD end-stage renal disease 
Table 2 Baseline demographics, co-morbidities, and type of surgery performed for the septic and surgical patients

\begin{tabular}{lll}
\hline Baseline demographics & & \\
& Septic patients & Surgical \\
\hline Number studied & 15 & 30 \\
Age & $56.9 \pm 14.0$ & $71.4 \pm 6.4$ \\
Male & $6 / 15$ & $20 / 30$ \\
Co-morbidities & & \\
Hypertension & 4 & 18 \\
Angina & 0 & 4 \\
Previous myocardial infarct & 1 & 7 \\
Congestive heart failure & 3 & 0 \\
Ethanol abuse & 2 & 0 \\
HIV infection & 1 & 0 \\
Hepatitis C infection & 1 & 0 \\
Diabetes & 4 & 5 \\
Chronic renal insufficiency & 2 & 1 \\
Chronic obstructive pulmonary disease & 2 & 2 \\
Type of surgery performed & & 9 \\
$\quad$ Vascular & & 13 \\
General surgery & & 2 \\
Thoracic & & \\
Urologic & & \\
\hline
\end{tabular}

Patients who died during the study, however, had a lower median AUT $\mathrm{S}_{\mathrm{ct}} \mathrm{O}_{2}<65 \%$ than patients who survived (4.5 [0.0-25.3] vs. 0.0 [0.0-0.6] \% $\mathrm{min}^{-1} \mathrm{hr}^{-1} ; p=$ 0.04; Table 3 and Fig. 1). There was no difference in the percentage time spent under a threshold of $65 \%$ between patients who survived and died, suggesting that it

Table 3 Relationship between magnitude of cerebral desaturation and primary and secondary outcomes

\begin{tabular}{|c|c|c|c|}
\hline Outcome & Outcome present & Outcome absent & $p$ value \\
\hline \multicolumn{4}{|c|}{ CAM positive } \\
\hline$\%$ Time & $0.0[0.0-1.5]$ & $0.0[0.0-0.3]$ & 0.79 \\
\hline AUT/h & $2.9[0.2-8.4]$ & $9.3[1.2-16.0]$ & 0.41 \\
\hline \multicolumn{4}{|l|}{ AKI } \\
\hline$\%$ Time & $2.0[0.7-6.3]$ & $2.1[0.8-21.5]$ & 0.51 \\
\hline AUT/h & $2.9[0.2-8.4]$ & $12.6[0.3-21.2]$ & 0.59 \\
\hline \multicolumn{4}{|l|}{ Death } \\
\hline \% Time & $0.9[0.0-7.2]$ & $0.0[0.0-0.3]$ & 0.43 \\
\hline AUT/h & $4.5[0.0-25.3]$ & $0.0[0.0-0.6]$ & 0.04 \\
\hline
\end{tabular}

There was no difference in $\mathrm{SctO}_{2}$ between groups with respect to the presence of acute kidney injury (AKI) nor being Confusion Assessment Method (CAM-ICU) positive. Patients who died had decreases in $\mathrm{SctO}_{2}$ of greater magnitude than those that survived. Data are presented as median [interquartile range]. Values are represented as median [interquartile range]

$\%$ Time percentage of time spent below an $\mathrm{SctO}_{2}$ of $65 \%$ AUT area under threshold $\left(\% \mathrm{~min}^{-1} \mathrm{hr}^{-1}\right)$ is the magnitude of desaturation that plays an important role in this outcome (Table 3 ).

The incidence or magnitude of decrease in $\mathrm{SctO}_{2}$ was not related to the severity of the patient's illness, as measured by SOFA or APACHE II scores (data not shown).

With respect to the variables that may affect cerebral blood flow (and therefore potentially cerebral saturation), there was no correlation between $\mathrm{S}_{\mathrm{ct}} \mathrm{O}_{2}$ and peripheral oxygen saturation, norepinephrine dose, mean arterial pressure (MAP), or fraction of inspired oxygen $\left(\mathrm{F}_{\mathrm{I}} \mathrm{O}_{2}\right)$ (Fig. $2 \mathrm{a}-\mathrm{c}$ ). However, there was a correlation between day 2 hemoglobin concentrations and both the percentage time below an $\mathrm{S}_{\mathrm{ct}} \mathrm{O}_{2}$ (Pearsons $r=-0.46$, Fig. 3a) and $\mathrm{SctO}_{2}$ AUT $<75 \%$ (Pearsons $r=-0.55$, Fig. 3b), with lower hemoglobin values being associated with more significant cerebral desaturations.

As a comparison group, we also looked the incidence and magnitude of decreases of cerebral saturation in 30 patients undergoing high-risk non-cardiac surgical procedures, a group known to be at high risk for decreases in $\mathrm{SctO}_{2}$. The surgical patients were significantly older (71 \pm 6 vs. $57.0 \pm 3.6$ years, $p<0.001)$ and were coming for a variety of high-risk procedures (see Table 2).

Nine of the surgical patients (30\%) experienced a decrease in their $\mathrm{SctO}_{2}$ to below $65 \%$. Patients in the septic shock group were significantly more likely to experience a cerebral desaturation than those in the surgical group (12/15 vs. 9/30; relative risk 2.7 [95\% CI 1.5-4.9], $p<0.01$; Table 4). The patients with septic shock also spent more time below an $\mathrm{SctO}_{2}$ threshold of $65 \%$ when compared with the patients undergoing highrisk surgery $(2.2 \%[0.9-10.9]$ vs. $0.0 \%[0.0-8.8], p=$ 0.03 , septic vs. surgical patients, respectively, see Table 4). The septic patients also had a greater magnitude of cerebral desaturation (based on AUT calculation) when compared with the surgical patients (3.1 [0.3-14.5] vs. 0.0 [0.0-6.9] \% $\mathrm{min}^{-1} \mathrm{hr}^{-1} ; p<0.05$, septic vs. surgical, respectively, see Table 4).

\section{Discussion}

Our study did not demonstrate any relationship between decreases in $\mathrm{SctO}_{2}$ and the incidence of delirium in patients admitted to the ICU with septic shock. We chose the $\mathrm{S}_{\mathrm{ct}} \mathrm{O}_{2}$ threshold of $65 \%$ as constituting a significant cerebral desaturation, based on work by other authors [10, 22-24]. We also did not demonstrate any relationship between decreases in $\mathrm{SctO}_{2}$ and the development of an AKI. We did however discover that patients who died from their septic shock had significantly larger decreases in their $\mathrm{SctO}_{2}$ compared with those who survived.

The lack of an association between decreases in $\mathrm{SctO}_{2}$ and delirium could potentially be due to several factors. First, the etiology of delirium is multifactorial, and exact causes of it are uncertain. Second, most of our patients 


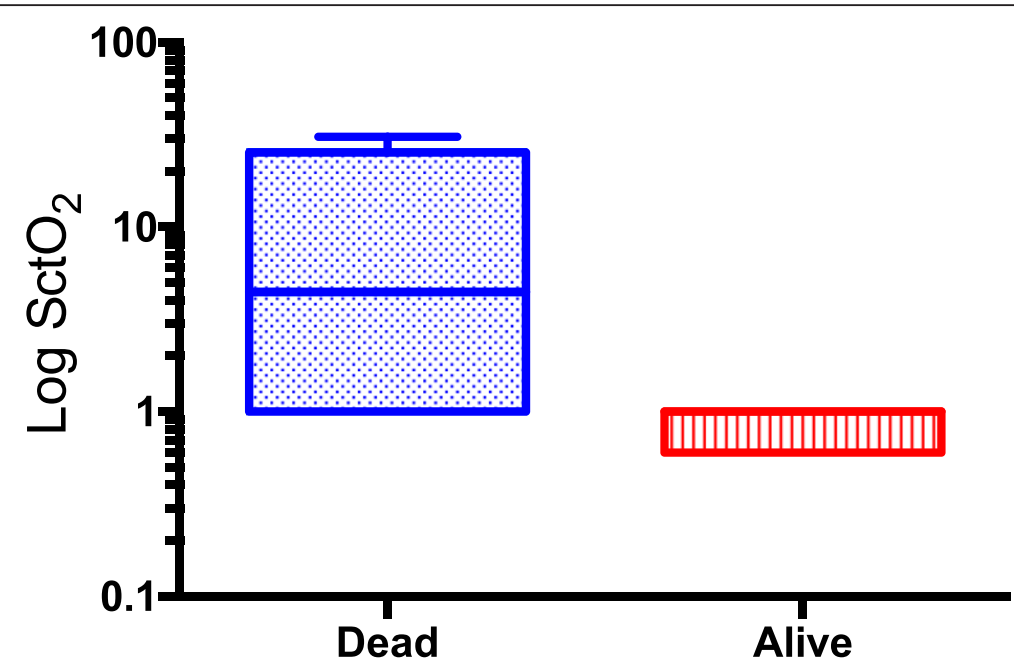

Fig. 1 Graphical representation of the Log AUT SctO ${ }_{2}$ of patients who died and survived their septic shock. Patients who died had a higher median AUT $\mathrm{S}_{\mathrm{ct}} \mathrm{O}_{2}<65 \%$ than patients who survived (4.5[0.0-25.3] vs. $\left.0.0[0.0-0.6] \% \mathrm{~min}^{-1} \mathrm{hr}^{-1} ; p=0.04\right)$

received benzodiazepines, a class of drugs that has been associated with postoperative delirium [25]. Finally, the cerebral oximeter we used only measures $\mathrm{SctO}_{2}$ from the frontal lobes and would not detect desaturations that take place in deeper cortical structures. Thus, we might be missing changes in $\mathrm{SctO}_{2}$ that occur in deeper parts of the brain that could predispose patients to delirium.

In our study, patients who died from septic shock had larger decreases in their $\mathrm{SctO}_{2}$ when compared with those patients who survived. Due to the small number of patients studied, it is possible that this is a spurious
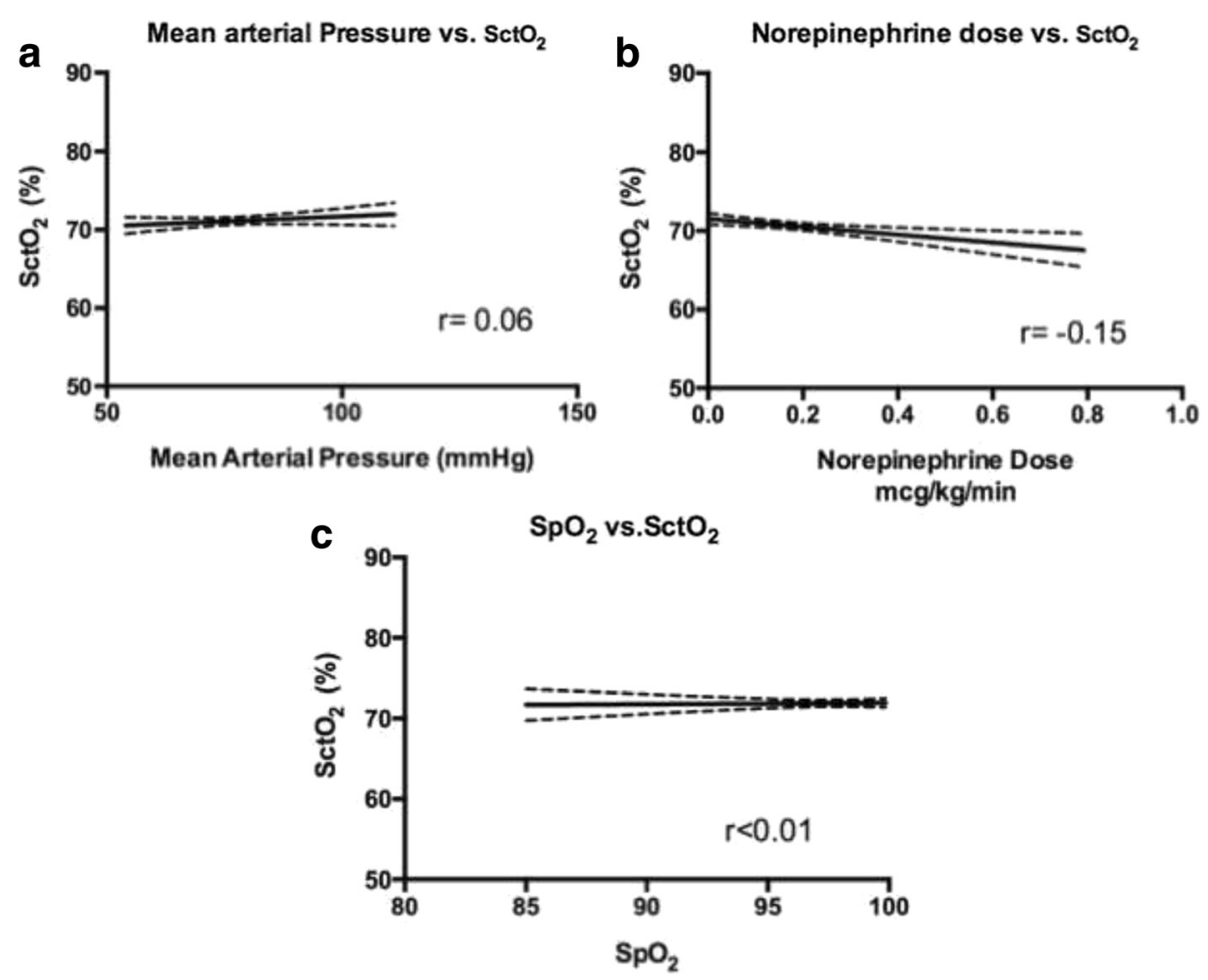

Fig. 2 Correlation between $\mathrm{SctO}_{2}$ values and $\mathbf{a}$ mean arterial pressure, $\mathbf{b}$ norepinephrine dose, and $\mathbf{c}$ peripheral oxygen saturation. There was no correlation between any of these variables and $\mathrm{SctO}_{2}$ (Pearsons r) 


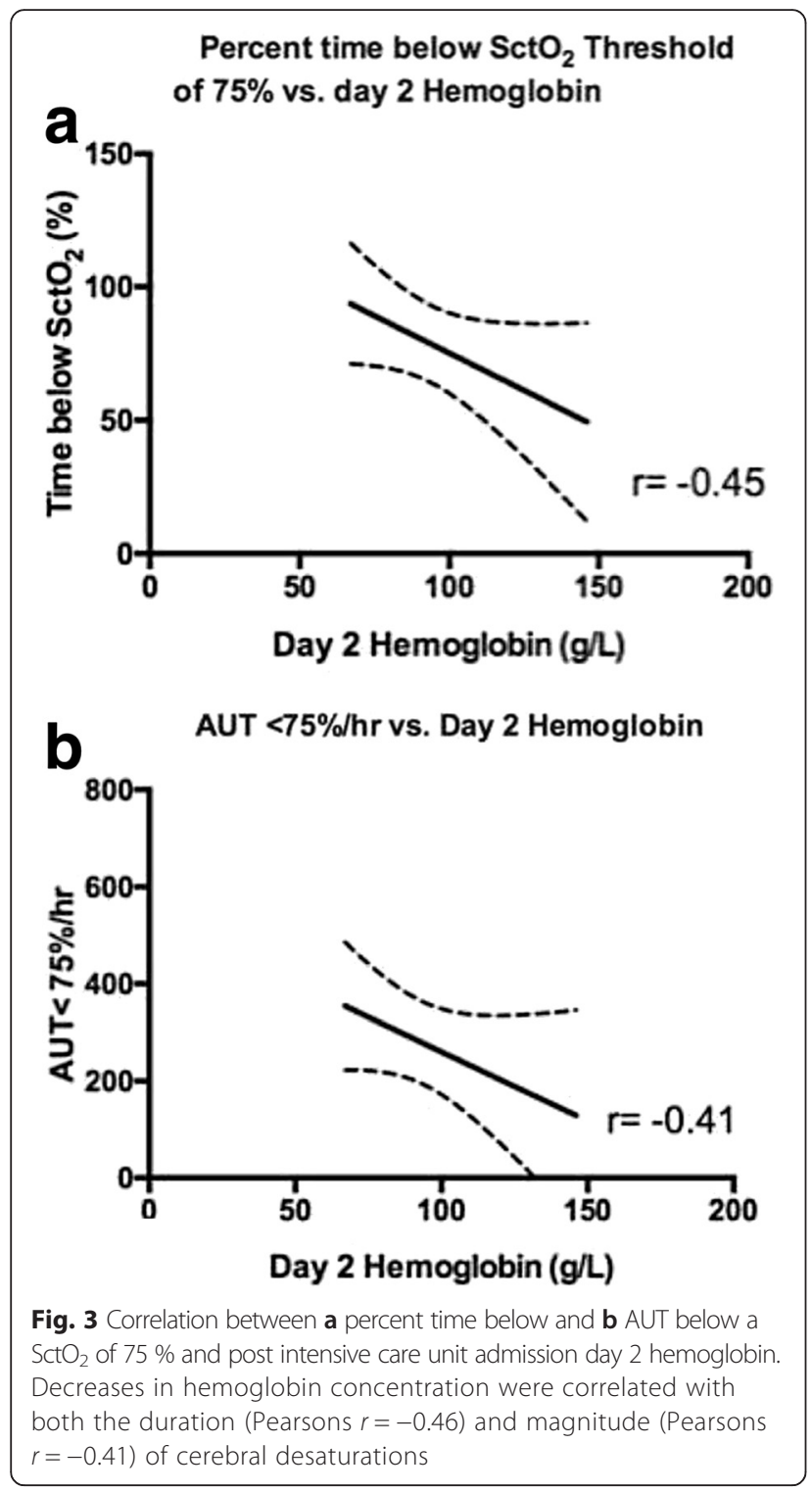

Table 4 Comparison of cerebral saturation between septic and surgical patients

\begin{tabular}{llll}
\hline Parameter & Septic & Surgical & $p$ value \\
\hline $\begin{array}{l}\text { Number of patients } \\
\text { with desaturations }\end{array}$ & $12 / 15$ & $9 / 30$ & $<0.01$ \\
$\begin{array}{l}\text { Percent time below } \\
\mathrm{SctO}_{2} \text { threshold }\end{array}$ & $2.2[0.9-10.9]$ & $0[0.0-8.8]$ & 0.03 \\
AUT/h & $3.1[0.3-14.5]$ & $0.0[0.0-6.9]$ & 0.04 \\
\hline
\end{tabular}

Septic patients had decreases in their $\mathrm{SctO}_{2}$ more frequently and of a greater magnitude than surgical patients. Data are presented as median [interquartile range]. The number of patients with desaturations was compared using Fisher's exact test, while percent time and AUT/Hr differences were compared with Mann-Whitney $U$ test

Percent time percentage of time spent below an $\mathrm{SctO}_{2}$ of $65 \%$ AUT area under threshold $\left(\% \mathrm{~min}^{-1} \mathrm{hr}^{-1}\right)$ finding. There is biological plausibility, however, for decreases in $\mathrm{SctO}_{2}$ being linked to death.

Animal studies have demonstrated that as global oxygen delivery is reduced, blood flow and therefore oxygen delivery to the brain is preserved [15]. This may explain the association between decreases in $\mathrm{SctO}_{2}$ and nonneurologic organ injury. The brain can be considered the organ of highest priority when it comes to tissue hypoperfusion during shock states. When oxygen delivery to the brain is decreased below a critical value, cerebral desaturations occur. In the context of septic shock, cerebral desaturation likely indicates that blood flow to the other vital organs has been severely compromised. Our work suggests that non-survivors of septic shock exhibit decreased $\mathrm{SctO}_{2}$ as a reflection of more severe global perfusion defects compared to survivors. Our study is obviously too small to confirm this, but is hypothesis generating.

When compared with a group of high-risk patients undergoing major non-cardiac surgery at our institution, patients with septic shock had a higher incidence and greater magnitude of cerebral desaturations. We chose high-risk surgical patients as a comparator group as it is known that these patients have high rates of cerebral desaturation and are at high risk for complications. The incidence of cerebral desaturations in our surgical patients is consistent with previous studies that showed a cerebral desaturation incidence of $20-$ $30 \%$ in patients undergoing elective non-cardiac surgery $[10,12,17,22,23]$. Our findings suggest that cerebral desaturations are more common and more severe in septic shock patients.

Other interesting findings from our study are the lack of relationship between $\mathrm{SctO}_{2}$ and peripheral oxygen saturation, $\mathrm{F}_{\mathrm{I}} \mathrm{O}_{2}, \mathrm{MAP}$, or vasopressor dose. With the knowledge that decreases in $\mathrm{SctO}_{2}$ are related to the outcome, there have been proposed treatment strategies to increase $\mathrm{SctO}_{2}$ in the hopes of improving the outcome [26]. These strategies include increasing MAP, increasing arterial carbon dioxide tension (to increase cerebral blood flow), increasing $\mathrm{F}_{\mathrm{I}} \mathrm{O}_{2}$, and increasing hemoglobin concentration with red blood cell transfusions. Our work suggests that, in septic patients, these variables (with the exception of hemoglobin concentration) do not correlate with cerebral saturation.

Other perioperative studies have pointed to anemia as a potential cause of adverse neurological outcomes [27]. However, the literature regarding the beneficial effects of blood transfusion in critical care is controversial, with the most recent study suggesting no benefit of higher hemoglobin levels in septic patients [28-30].

Limitations to our study include the small number of patients studied and the varying etiologies of sepsis and the different baseline co-morbidities. A much larger 
study will have to be undertaken to determine if there is truly no relationship between cerebral desaturations and delirium.

Finally, the issue of extracranial contamination might have affected our results [31]. Briefly, extracranial contamination occurs when desaturated blood below the skin is measured by the device and interpreted as being intracranial in nature. With the aggressive fluid resuscitation that our patients were receiving, it is possible that the edema that results from fluid administration might have resulted in spuriously lower levels of measured $\mathrm{SctO}_{2}$.

\section{Conclusions}

Our study suggests that decreases in $\mathrm{SctO}_{2}$ occur frequently in patients with septic shock. These decreases are of a larger magnitude than in a group of patients undergoing high-risk non-cardiac surgery. Decreases in $\mathrm{SctO}_{2}$ are not related to ICU delirium, but may be related to the risk of death in the ICU. Finally, there appears to be no relationship between the incidence or magnitude of decreases in $\mathrm{SctO}_{2}$ and physiological parameters (such as $\mathrm{F}_{1} \mathrm{O}_{2}$, MAP, or vasopressor dose). However, decreases in hemoglobin concentration appear to correlate with changes in $\mathrm{SctO}_{2}$.

\section{Ethics approval}

This report describes human research. IRB contact information: Bannatyne Research Ethics Board, P126 Pathology Building, 770 Bannatyne Avenue, University of Manitoba, Winnipeg, MB R3E 0W3. Phone: 204 789-3255. Fax: 204 789-3414. This study was conducted with written informed consent from the study subjects. The study was registered prior to patient enrollment as B2011:138. Registry URL: ClinicalTrials.gov Identifier: NCT1836302. Registered on April 16, 2013.

\section{Abbreviations \\ AKI, acute kidney injury; APACHE II, Acute Physiology and Chronic Health Evaluation II; AUT, area under threshold; CAM-ICU, Confusion Assessment Method for the Intensive Care Unit; $\mathrm{F}_{1} \mathrm{O}_{2}$, fraction of inspired oxygen; MAP, mean arterial pressure; $\mathrm{SctO}_{2}$, brain tissue oxygen saturation; SOFA, Sequential organ failure assessment}

\section{Competing interests}

All authors declare that they have no competing interests.

\footnotetext{
Authors' contributions

DF helped design the study, conduct the study, analyze the data, and write the manuscript. DF has seen the original study data, reviewed the analysis of the data, approved the final manuscript, and is the author responsible for archiving the study files. AK helped analyze the data and write the manuscript. AK has seen the original study data, reviewed the analysis of the data, and approved the final manuscript. GK helped design the study, conduct the study, analyze the data, and write the manuscript. GK has seen the original study data, reviewed the analysis of the data, and approved the final manuscript.
}

\section{Acknowledgements}

The authors would like to thank the University of Manitoba Department of Anesthesiology and Perioperative Medicine for their financial support of this project.

Funding

The University of Manitoba Department of Anesthesiology and Perioperative Medicine funded this study.

Received: 13 March 2016 Accepted: 21 June 2016

Published online: 29 June 2016

\section{References}

1. Kaukonen K, Bailey M, Suzuki S, Pilcher D, Bellomo R. Mortality related to severe sepsis and septic shock among critically ill patients in Australia and New Zealand, 2000-2012. JAMA. 2014;311:1308-16.

2. Christaki E, Opal SM. Is the mortality rate for septic shock really decreasing? Curr Opin Crit Care. 2008;14:580-6.

3. Investigators A, Group ACT, Peake SL, et al. Goal-directed resuscitation for patients with early septic shock. N Engl J Med. 2014;371:1496-506.

4. Mouncey PR, Osborn TM, Power GS, et al. Trial of early, goal-directed resuscitation for septic shock. N Engl J Med. 2015;372:1301-11.

5. Pro Cl, Yealy DM, Kellum JA, et al. A randomized trial of protocol-based care for early septic shock. N Engl J Med. 2014;370:1683-93.

6. Morandi A, Jackson JC. Delirium in the intensive care unit: a review. Neurol Clin. 2011;29:749-63.

7. Zaal IJ, Devlin JW, Peelen LM, Slooter AJ. A systematic review of risk factors for delirium in the ICU. Crit Care Med. 2015:43:40-7.

8. Weinhouse GL. Delirium and sleep disturbances in the intensive care unit: can we do better? Curr Opin Anaesthesiol. 2014:27:403-8.

9. Reade MC, Finfer S. Sedation and delirium in the intensive care unit. N Engl J Med. 2014:370:444-54.

10. Casati A, Fanelli G, Pietropaoli P, et al. Monitoring cerebral oxygen saturation in elderly patients undergoing general abdominal surgery: a prospective cohort study. Eur J Anaesthesiol. 2007;24:59-65.

11. Colak Z, Borojevic M, Ivancan V, Gabelica R, Biocina B, Majeric-Kogler V. The relationship between prolonged cerebral oxygen desaturation and postoperative outcome in patients undergoing coronary artery bypass grafting. Coll Antropol. 2012;36:381-8.

12. Kazan R, Bracco D, Hemmerling TM. Reduced cerebral oxygen saturation measured by absolute cerebral oximetry during thoracic surgery correlates with postoperative complications. Br J of Anaesth. 2009;103:811-6.

13. Tang L, Kazan R, Taddei R, Zaouter C, Cyr S, Hemmerling TM. Reduced cerebral oxygen saturation during thoracic surgery predicts early postoperative cognitive dysfunction. Br J Anaesth. 2012;108:623-9.

14. Slater JM, Orszulak TA, Cook DJ. Distribution and hierarchy of regional blood flow during hypothermic cardiopulmonary bypass. Ann Thorac Surg. 2001:72:542-7.

15. Boston US, Slater JM, Orszulak TA, Cook DJ. Hierarchy of regional oxygen delivery during cardiopulmonary bypass. Ann Thorac Surg. 2001;71:260-4.

16. Ely EW, Inouye SK, Bernard GR, et al. Delirium in mechanically ventilated patients: validity and reliability of the confusion assessment method for the intensive care unit (CAM-ICU). JAMA. 2001;286:2703-10.

17. Casati A, Fanelli G, Pietropaoli P, et al. Continuous monitoring of cerebral oxygen saturation in elderly patients undergoing major abdominal surgery minimizes brain exposure to potential hypoxia. Anesth Analg. 2005;101:7407. table of contents.

18. Bone RC, Balk RA, Cerra FB, et al. Definitions for sepsis and organ failure and guidelines for the use of innovative therapies in sepsis. The ACCP/SCCM Consensus Conference Committee. American College of Chest Physicians/ Society of Critical Care Medicine. Chest. 2009;136:e28.

19. Dellinger RP, Levy MM, Carlet JM, et al. Surviving Sepsis Campaign: international guidelines for management of severe sepsis and septic shock: 2008. Crit Care Med. 2008:36:296-327.

20. Mehta RL, Kellum JA, Shah SV, et al. Acute Kidney Injury Network: report of an initiative to improve outcomes in acute kidney injury. Crit Care. 2007:11:R31.

21. Viechtbauer W, Smits L, Kotz D, et al. A simple formula for the calculation of sample size in pilot studies. J Clin Epidemiol. 2015:68:1375-9.

22. Fischer GW, Lin HM, Krol M, et al. Noninvasive cerebral oxygenation may predict outcome in patients undergoing aortic arch surgery. J Thorac Cardiovasc Surg. 2011;141:815-21. 
23. Fudickar A, Peters S, Stapelfeldt C, et al. Postoperative cognitive deficit after cardiopulmonary bypass with preserved cerebral oxygenation: a prospective observational pilot study. BMC Anesthesiol. 2011;11:7.

24. Casati A, Spreafico E, Putzu M, Fanelli G. New technology for noninvasive brain monitoring: continuous cerebral oximetry. Minerva Anestesiol. 2006;72:605-25.

25. Vasilevskis EE, Han $\mathrm{H}$, Hughes $\mathrm{CG}$, Ely EW. Epidemiology and risk factors for delirium across hospital settings. Best Pract Res Clin Anaesthesiol. 2012;26:277-87.

26. Denault A, Deschamps A, Murkin JM. A proposed algorithm for the intraoperative use of cerebral near-infrared spectroscopy. Semin Cardiothorac Vasc Anesth. 2007;11:274-81.

27. Devereaux PJ, Yang H, Yusuf S, et al. Effects of extended-release metoprolol succinate in patients undergoing non-cardiac surgery (POISE trial): a randomised controlled trial. Lancet. 2008;371:1839-47.

28. Hebert PC, Wells G, Blajchman MA, et al. A multicenter, randomized, controlled clinical trial of transfusion requirements in critical care. Transfusion Requirements in Critical Care Investigators, Canadian Critical Care Trials Group. N Engl J Med. 1999;340:409-17.

29. Rivers E, Nguyen B, Havstad S, et al. Early goal-directed therapy in the treatment of severe sepsis and septic shock. N Engl J Med. 2001;345:1368-77.

30. Holst LB, Haase N, Wetterslev J, et al. Lower versus higher hemoglobin threshold for transfusion in septic shock. N Engl J Med. 2014;371:1381-91.

31. Davie SN, Grocott HP. Impact of extracranial contamination on regional cerebral oxygen saturation: a comparison of three cerebral oximetry technologies. Anesthesiology. 2012;116:834-40.

\section{Submit your next manuscript to BioMed Central} and we will help you at every step:

- We accept pre-submission inquiries

- Our selector tool helps you to find the most relevant journal

- We provide round the clock customer support

- Convenient online submission

- Thorough peer review

- Inclusion in PubMed and all major indexing services

- Maximum visibility for your research

Submit your manuscript at www.biomedcentral.com/submit 